\title{
Black carbon and dust alter the response of mountain snow cover under climate change
}

\section{Marion REVEILLET ( $\nabla$ marion.reveillet@meteo.fr)}

Univ. Grenoble Alpes, Université de Toulouse, Météo-France, CNRS, CNRM, Centre d'Etudes de la Neige, 38000 Grenoble, France https://orcid.org/0000-0001-9802-4649

Marie Dumont

Météo-France-CNRS https://orcid.org/0000-0002-4002-5873

\section{Simon Gascoin}

Centre d'Etudes Spatiales de la Biosphère (CESBIO), Université de Toulouse, CNRS/CNES/IRD/INRAE/UPS, 31400 Toulouse, France

\section{Matthieu Lafaysse}

Univ. Grenoble Alpes, Université de Toulouse, Météo-France, CNRS, CNRM, Centre d'Etudes de la Neige, Grenoble, France

\section{Pierre Nabat}

CNRM-GAME

\section{Aurélien Ribes}

Centre National de Recherches Météorologiques https://orcid.org/0000-0001-5102-7885

\section{Rafife Nheili}

Univ. Grenoble Alpes, Université de Toulouse, Météo-France, CNRS, CNRM, Centre d'Etudes de la Neige, 38000 Grenoble, France

\section{François Tuzet}

Univ. Grenoble Alpes, Université de Toulouse, Météo-France, CNRS, CNRM, Centre d'Etudes de la Neige, Grenoble

\section{Martin Menegoz}

University de GRenoble

\section{Samuel Morin}

Univ. Grenoble Alpes, Université de Toulouse, Météo-France, CNRS, CNRM, Centre d'Etudes de la Neige, Grenoble, France https://orcid.org/0000-0002-1781-687X

\section{Ghislain Picard}

Laboratoire de Glaciologie et Géophysique de l'Environnement, CNRS/Université Joseph Fourier de Grenoble

\section{Paul Ginoux}

National Oceanic and Atmospheric Administration 


\section{Article}

Keywords: snowmelt, water availability, snow cover decline

Posted Date: September 9th, 2021

DOl: https://doi.org/10.21203/rs.3.rs-800501/v1

License: (c) (i) This work is licensed under a Creative Commons Attribution 4.0 International License. Read Full License

Version of Record: A version of this preprint was published at Nature Communications on September 20th, 2022. See the published version at https://doi.org/10.1038/s41467-022-32501-y. 


\section{Black carbon and dust alter the response of mountain snow cover under climate change}

Marion Réveillet ${ }^{1 *}$, Marie Dumont ${ }^{1 *}$, Simon Gascoin ${ }^{2}$, Matthieu Lafaysse ${ }^{1}$, Pierre Nabat ${ }^{3}$, Aurélien Ribes ${ }^{3}$, Rafife Nheili ${ }^{1}$, Francois Tuzet ${ }^{1}$, Martin Ménégoz ${ }^{4}$, Samuel Morin ${ }^{3}$, Ghislain Picard ${ }^{4}$, Paul Ginoux ${ }^{5}$

${ }^{1}$ Univ. Grenoble Alpes, Université de Toulouse, Météo-France, CNRS, CNRM, Centre d'Etudes de la Neige, 38000 Grenoble, France

${ }^{2}$ Centre d'Etudes Spatiales de la Biosphère (CESBIO), Université de Toulouse, CNRS/CNES/IRD/INRAE/UPS, 31400 Toulouse, France

${ }^{3}$ CNRM, Université de Toulouse, Météo-France, CNRS, Toulouse, France ${ }^{4}$ Univ. Grenoble Alpes, CNRS, IRD, IGE, 38000 Grenoble, France

${ }^{5}$ NOAA Geophysical Fluid Dynamics Laboratory, 201 Forrestal Road, Princeton, NJ 08540, USA

*To whom correspondence should be addressed; E-mail: marion.reveillet@ meteo.fr, marie.dumont@meteo.fr

By darkening the snow surface, mineral dust and black carbon (BC) deposition enhances snowmelt and triggers numerous feedbacks. Assessments of their long-term impact at the regional scale are still largely missing despite the environmental and socio-economic implications of snow cover changes. Here we show, using numerical simulations, that dust and $\mathrm{BC}$ deposition has advanced snowmelt by 17 days on average in the French Alps and the Pyrenees over the 1979-2018 period, with major implications for water availability. We demonstrate that the decrease in $\mathrm{BC}$ deposition since the 1980s moderates the impact of current warming on snow cover decline. Hence, accounting for changes in light-absorbing particles deposition is required to improve the accuracy of snow cover reanalyses and climate projections, that are crucial for better understanding the past and future evolution of mountain social-ecological systems. 
Snow cover changes have drastic consequences for numerous components of the Earth system such as water resources $(1,2)$, ecosystems $(3,4)$ and the Earth climate through complex feedbacks $(5)$. In response to climate change, the snow cover duration in mountain areas has declined at the global scale since the 1950 s, on average by 5 days per decade at low elevations $(6,7)$. As a response to snow cover decline and enhanced snowmelt, the peak runoff from snowmelt has shifted by around 10 days on average over the 1965-2005 period for the Alps (8). Changes both in the magnitude and timing of the snowmelt runoff threaten the availability of water resources in downstream regions, and in particular for irrigation (2). Snow cover trends are mostly attributed to changes in atmospheric drivers, and especially to the warming that intensified over the last decades to reach $0.3 \pm 0.2^{\circ} \mathrm{C}$ per decade for mountainous areas at global scale (6).

Light-absorbing particles (LAPs) such as black carbon (BC), brown or organic carbon, mineral dust and algae are potent drivers of snow cover changes (9-11). LAPs darken the snow surface when deposited on the snow cover and amplify several snow-albedo feedback loops, drastically modifying the snow cover evolution and duration (12). LAPs indeed accelerate the coarsening of the snow microstructure, leading to more solar energy absorption and to an acceleration of the intrinsic snow albedo feedback (13). Moreover, LAPs are partially retained at the snow surface during melt, amplifying the decrease in the albedo (14). The impact of LAPs on the snow cover is, thus, modulated by meteorological conditions, leading to complex interplays between the LAPs and the meteorological drivers of the snow cover evolution (5).

$\mathrm{BC}$ is the most efficient absorbing aerosol in the atmosphere $(12,15)$ and its deposition strongly impacts snowmelt rates (12). In central Europe, an increase in BC deposition since 1850 has been observed until the 1970s due to anthropogenic activities (16). It has been suggested that $\mathrm{BC}$ deposition contributed to the triggering of glacier retreat in the Alps (16). However, $\mathrm{BC}$ deposition has decreased since the 1980s (17), due to a reduction of emissions likely related primarily to traffic emission decrease (18). However, the impact of this recent negative trend on snow cover has not been quantified hitherto.

Even if mineral dust deposition events are generally more episodic than $\mathrm{BC}$ deposition $(19,20)$, they can have a widespread visible impact on the snow surface (e.g. in Feb. 2021, (21)), with a prevailing radiative effect compared to $\mathrm{BC}(19,22)$. In Europe, mountain ranges are generally affected by dust deposition events originating from the Sahara, which contribute to $50-70 \%$ of the total annual dust de- 
position (23). Yet, the strong spatial and temporal variability combined with the lack of long-term data make it difficult to identify trends over the last decades (24).

Regional assessments of the combined effect of LAPs deposition on snow cover changes over long time periods are currently missing $(6,12)$. Here, we quantify the combined effect of $\mathrm{BC}$ and dust deposition on snow cover dynamic and trends at the regional scale of the French Alps and Pyrenees mountain ranges, for the 1979-2018 period. Considering the large uncertainty in brown carbon deposition and absorption efficiency (12), the effect of brown carbon is excluded from the analysis as well as the effect of algae that generally bloom only at high elevation and late in spring (25). Our analysis is based on numerical simulations performed with the detailed snow cover model Crocus accounting for the complex interactions between LAPs and snow (26).

\section{Results}

Simulations explicitly accounting for dust and BC deposition fluxes are compared to a pure snow simulation, excluding any LAP. Simulations are driven by the meteorological reanalysis S2M (27) and BC and dust deposition fluxes from the regional climate model CNRM-ALADIN63 driven by reanalysis data (so as to follow the unfolding of observed meteorological conditions) (28). To quantify the impact of BC and dust on snow cover evolution we used the snow melt-out date (SMOD), defined as the last date of the annual longest period with at least $30 \mathrm{~cm}$ of snow. This indicator is relevant for water resources and ecosystem impacts of the seasonal snow cover $(6)$. The snow cover simulations were evaluated against satellite observation of the snow cover area and in situ observations of melt rates using 495 stations measuring snow depth (See Methods). Simulations accounting for BC and dust systematically lead to better scores compared to pure snow simulations.

\section{Shortening of the season due to $\mathrm{BC}$ and dust}

The comparison of the pure snow simulations with the simulations accounting for $\mathrm{BC}$ and dust show that, by darkening the snow surface, the combined effect of $\mathrm{BC}$ and dust leads to an earlier snow meltout date (SMOD) by 17.8 and 16.1 days on average in the French Alps and Pyrenees, respectively, over the 1979-2018 period (Fig. 1). These reductions correspond to 9.1 and $8.8 \%$ of the mean annual snow 
cover duration. These averages are calculated accounting for the relative surface at each elevation bands in both mountain ranges. The SMOD reduction varies from 0 to 47 days across the domain (Fig. 1). Variations depend on the year (Supplementary Fig. S1), due to strong BC and dust variations over time (Supplementary Fig. S2). Variations also depend on the area and the elevation. A larger absolute impact of $\mathrm{BC}$ and dust on the SMOD in number of days is found at higher elevations. This is related to later melt and longer snow season, where dust and $\mathrm{BC}$ are exposed to higher incoming solar radiation, amplifying its effect on snowmelt acceleration (29).

The effect of $\mathrm{BC}$ is prevailing in the Northern part of the French Alps and Pyrenees, where higher BC deposition is observed (Supplementary Fig. S2). The simulated SMOD when accounting only for BC is earlier on average by 14.2 days (7.1\%) in the Northern Alps and by 13.3 days (6.9\%) in the Southern Alps, compared to the pure simulation. The Southern parts of both mountain ranges are more exposed to Saharan dust deposition (Supplementary Fig. S2), and exhibit larger dust deposition amounts than the Northern parts. However the effect of dust deposition is prevailing only at higher elevation in the Southern parts where the snow cover melts earlier by 3.7 days (1.9\%) on average when accounting for dust only than when accounting for BC only.

Figure 1 also shows the SMOD reduction between the pure snow simulation and a simulation named "baseline" that accounts only implicitly for the LAPs by decreasing albedo as a function of time since the last snowfall without any link to the actual LAP concentration. This simple treatment of the radiative impact of LAPs, only represented by a darkening of the surface snow over time, is the most common practice in snow modeling (30) but has the disadvantage of neglecting spatial or temporal variations of the LAPs deposition fluxes (see Methods). The simulated SMOD in the baseline configuration is later compared to the explicit simulation on averaged by 7.3 days for the Alps and 9.3 days for the Pyrenees

(Fig. 1). This suggests that the temporal and spatial variability of the $\mathrm{BC}$ and dust deposition fluxes likely has an important effect on the snow cover duration.

\section{$\mathrm{BC}$ and dust effect on snow cover inter-annual variability}

Based on an analysis of the variance (ANOVA, (31), Method and Supplementary text), we quantify the contribution of the different atmospheric drivers to the SMOD inter-annual variability (see Methods). The combined effect of the $\mathrm{BC}$ and dust explains up to $30.7 \%$ of the variance of the SMOD at $2100 \mathrm{~m}$ 
a.s.1. in the Alps (Fig. 2, total variance of $329 \mathrm{~d}^{2}$ ) and up to $21.8 \%$ in the Pyrenees (for a total variance of $\left.578 \mathrm{~d}^{2}\right)$.

$\mathrm{BC}$ and dust contributions depend on the meteorological conditions (32). For instance, the same amount of $\mathrm{BC}$ and dust deposited at the snow surface has a stronger impact if a large time period between two snowfalls occurs, than when a snowfall occurs immediately after the deposition. To evaluate this effect we separate the contribution of the $\mathrm{BC}$ and dust only to the total variance (named the additive part) and the contribution of $\mathrm{BC}$ and dust that cannot be separated from the meteorological conditions (named the sequencing part). This sequencing of meteorological conditions and $\mathrm{BC}$ and dust deposition contributes to $2.9-9.1 \%$ to the total variance, while the additive part contributes to $12.7-25.5 \%$ of the total variance (Fig. 2). These results indicate a marked contribution of $\mathrm{BC}$ and dust to the variance of the SMOD that depends on the meteorological conditions especially in the Southern mountain ranges.

The $\mathrm{BC}$ and dust contribution to the SMOD inter-annual variability is larger in the Alps than in the Pyrenees, mostly related to a higher contribution of the $\mathrm{BC}$ deposition. BC deposition contributes to 19.3 and $12.4 \%$ to the total variance of the SMOD for the Northern and Southern Alps, and to 6.2 and 5.9\% for the Northern and Southern Pyrenees, respectively. BC contribution to the SMOD inter-annual variability is generally higher than dust contribution, except for the Southern Pyrenees, more affected by episodic dust outbreaks (33).

In summary, our results show that $\mathrm{BC}$ and dust are significant drivers of the SMOD inter-annual variability. The calculation of their contribution has been performed on the 39 years time series without detrending and thus including the effects of atmospheric trends, such as trends in air temperature and BC and dust deposition, over this period.

\section{Past trends (1979-2018)}

The simulated SMOD for pure snow (without considering the BC and dust effect) follows a negative trend over the last decades (1979-2018) indicating earlier snowmelt (Fig. 3). For instance, the SMOD decrease at $2100 \mathrm{~m}$ a.s.l. is 7.8 days per decade (corresponding to a $4.0 \%$ shorter snow season) for the Northern Alps and 6.4 days per decade (4.0\%) for the Southern Alps. This decrease is consistent with the positive trend in air temperature. According to the reanalysis data used in this study, significant temperature trends range from 0.1 to $0.3^{\circ} \mathrm{C}$ per decade (Fig. 3). The SMOD decreasing trend simulated 
in the Pyrenees is smaller than in the Alps and consistent with the trend in air temperature.

The trend in simulated BC deposition over the winter period for the last decades (1979-2018) is negative (Fig. 3), with a decrease of $11 \%$ on average considering all the massifs. Simulations accounting for $\mathrm{BC}$ deposition leads to a negative SMOD trend lower than the SMOD trend of the pure snow case (Fig. 3). For instance, the SMOD decrease at $2100 \mathrm{~m}$ a.s.l. is of 5.2 days per decade for the Northern Alps (corresponding to a decrease of $2.6 \%$ of the snow season duration), 4.0 for the Southern Alps (2.5\%). This means that, at the beginning of the study period (1979-1988), the shortening attributed to BC deposition alone (i.e. 15 days on average for all the areas) is higher than for the recent period (2009-2018) (i.e. 10 days only in average). Thus, reduced BC deposition fluxes partly offset the effect of rising temperature because less BC on the snow surface decreases melting rates by reducing solar energy absorption.

Conversely, no significant trend in dust deposition is identified (Fig 3). Dust deposition consequently does not significantly affect the SMOD trend. The decrease in SMOD trend from simulations accounting for both BC and dust deposition is thus, due to the decrease in BC deposition since the 1980s. This decrease compensates part of the impact of warming on the trend of the snow cover duration at $2100 \mathrm{~m}$ a.s.l. and is observed for all the Alps and Pyrenees (Supplementary text and Fig. S3) However, trends presented in this section originate from one model and the limitations are therefore discussed below.

\section{Impacts on mountain hydrology}

By exerting a strong control on the snow cover ablation rate, $\mathrm{BC}$ and dust deposition also has a profound influence on melt water runoff. To quantify this effect, we use the Center of Mass Date (CMD), defined as the date for which half of the total annual runoff from snowmelt is reached (34). BC and dust lead to a shift in the simulated CMD by up to 15 days earlier in the season (Fig. 4) over the 1979-2018 period compared to pure snow simulations. The effect is larger in the Alps (CMD shift of 15 days for the Alps) than for the Pyrenees (CMD shift of 10 days) in agreement with the larger effect on snow cover duration in the Alps mentioned above. No significant change in the intensity of the peak runoff can be attributed to the presence of $\mathrm{BC}$ and dust (Fig. 4). Even if the magnitude of the peak runoff is preserved, earlier snowmelt can have a profound consequences on the management of the water resource and downstream alpine ecosystems (35). The combined effect of $\mathrm{BC}$ and dust explains up to 5.4 days of the CMD variance (37\% of the total variance, Supplementary Fig. S4). This is in agreement with the contribution of BC 
and dust found for the SMOD variance with a prevailing contribution of $\mathrm{BC}$ deposition on the Northern ranges and dust deposition in the Southern ranges. The observed changes in the timing of the peak runoff attributed to climate change over the 1965-2005 period are of around 10 days for the Alps (8). The simulated CMD shift of 10 to 15 days attributed to the presence of $\mathrm{BC}$ and dust here is thus comparable in magnitude.

Finally, our results indicate that the shift of the CMD due to warming would be stronger if not compensated by a decrease in BC deposition over the 1979-2018 period (Fig. 3). When considering only BC deposition, the trend in CMD would decrease by 1.3 days per decade on average, with a larger impact (of 2 days per decade) in the Northern Alps, explained by a stronger negative trend in BC deposition (Fig. $3)$.

\section{Relevance and implications}

This study analyses the impact of dust and $\mathrm{BC}$ deposition on seasonal snow cover variability and trends in the French Alps and Pyrenees, using regional meteorological and deposition reanalysis and the detailed snow cover model Crocus. We demonstrate that $\mathrm{BC}$ and dust have a major role in advancing the snow cover melt, with a strong influence on the inter-annual variability of the snow cover and drastic implications for water availability timing. We also show that the response of the snow cover evolution to climate change is strongly modulated by the $\mathrm{BC}$ and dust deposition fluxes, suggesting that trends in snow cover and LAPs deposition cannot be investigated independently.

Our results also show that the impact of BC and dust on SMOD depends strongly on elevation, in terms of their influence on snowmelt timing (Fig. 1) (29). Indeed when snow is melting later in the spring (e.g., high elevation) more incoming shortwave energy is available, enhancing the radiative impact of LAPs. However, these altitudinal variations are superimposed with regional contrasts in the controlling factors of SMOD changes. The BC and dust deposition leads to larger effect on snow cover duration in the Alps compared to the Pyrenees directly related to higher BC deposition in the Alps (Supplementary Fig. S2). The relative impact of dust compared to the one of $\mathrm{BC}$ is higher for the South Pyrenees than for the Alps. This is explained by the regional patterns of African dust deposition that decreases with the distance to the North African coasts according to a south-north gradient (33) and by the general 
predominance of African over local sources in the total dust load (36). We can thus expect similarly large regional contrast in the impact of LAPs on snow cover in other mountainous regions.

Strong regional and altitudinal contrasts in $\mathrm{BC}$ and dust deposition has also been found for other mountain ranges as recently evidenced in High Mountain Asia (22). They showed a prevailing of dust effect on snowmelt at high elevation, especially in the Western regions. The BC and dust load is about twice higher in these areas than in the Alps and the Pyrenees. The snow cover duration shift induced by BC and dust in High Mountain Asia is thus likely higher than the 17 days reported in our study for the French Alps and Pyrenees.

Similarly strong regional contrasts arise in the trends of $\mathrm{BC}$ and dust deposition. Negative trends in BC deposition has been observed since the 1980s in Europe but also in North America and in the Arctic $(37,38)$. In contrast, positive trends have been reported in Asia, Oceanic regions and Antarctica (37). Such positive trends may result in enhancing the effect of global warming on snow cover duration. Regarding dust deposition, no trend is evidenced for most of the mountain regions, partly due to the strong annual variability of dust deposition and the limited record duration (24). However, a positive trend in deposition was observed in the Caucasus likely due to increasingly dry conditions in North Africa and the middle East (39). As exemplified in our study, these regional contrasts in deposition trend modulates the regional response of the snow cover to climate change.

\section{Limitations}

Atmospheric and snow cover trends studied here originate from a single land surface mode driven by a single one meteorological reanalysis (S2M). However, the snow cover trend from our simulations accounting for BC and dust is in line with the observed trends in Alps and Pyrenees $(7,40-42)$ (see Methods). Besides, the results of our study are mostly based on relative differences between simulations and not on absolute values, therefore mitigating the impact of uncertainties in the meteorological variables and in the surface model. The trend in $\mathrm{BC}$ deposition originating from one atmospheric model reported in this study is in agreement with the negative trend observed in Europe since the 80's, as reported in many studies $(18,43,44)$, and in total conformity with the trend in $\mathrm{BC}$ deposition originating from the atmospheric model GFDL-AM4 (45) (Supplementary Fig. S2). 
In this study, we considered only two types of LAPs, BC and dust, while other types may also contribute to modify the radiative forcing on the snow cover. Brown carbon was excluded considering the high uncertainty in atmospheric concentrations and optical properties estimates (12). Snow algae could play an important contribution to snow cover in some regions such as Greenland (46) but their impact on seasonal snow in the European Alps is not yet bounded and their impact is limited to the very end of the snow season and for high elevations (typically above $2000 \mathrm{~m}$ a.s.l.) $(25,47)$. BC and dust are thus assumed to hold the dominant role in accelerating snow melt. BC and dust optical properties vary considerably $(48,49)$. The sensitivity to dust refractive index is investigated and the selected index in the study results in median impact (Supplementary Fig. S5). The sensitivity of our results to this parameter points out a need to better characterize the optical properties of Saharan dust after long-range transport and deposition in snow. The absorption efficiency of $\mathrm{BC}$ is also prone to large uncertainties (50) especially in snow (48) and is expected to impact our results. The absorption efficiency chosen here is a moderate value between extremes found in the literature (32).

Bias might also originates from the choice of a scavenging coefficient of $\mathrm{BC}$ and dust with melt water and from the choice of a given snow model. This was quantified using an ensemble approach with 35 configurations of the snow model showing that the deterministic simulation presented here give a slightly lower estimate of the impact of $\mathrm{BC}$ and dust on SMOD compared to the ensemble simulation (Supplementary Fig. S6). However, both estimates are close and the temporal trend is conserved. Finally, $\mathrm{BC}$ and dust in the atmosphere may lead to an atmospheric cooling before their deposition on the surface. Further research would be required to investigate simultaneously the snow cover changes induced by the deposition and the potential compensating effect of the particles in the atmosphere.

\section{Concluding remarks}

Our results demonstrate that $\mathrm{BC}$ and dust deposition advances the end of the snow season by 17 days on average over the French Alps and the Pyrenees mountain ranges. This reduction shifts up to 15 days in the availability of water from snowmelt. This has potential environmental and socio-economic impacts. The BC effect is generally prevailing over the dust effect, especially in the Northern part of the massifs. $\mathrm{BC}$ deposition alone, shortens the snow season by 11 days on average, compared to pure snow 
simulations. However, the BC effect would be even larger without the decrease in deposition observed since the 1980s. At the beginning of the study period (1979-1988), a shortening of 15 days is attributed to BC deposition alone. On the contrary, for the recent period (2009-2018), the shortening due to BC is of 10 days only on average. This emphasizes the key effect of changes in $\mathrm{BC}$ deposition on the snow cover. Due to the current warming, the snow cover decline would be even more pronounced without the opposing effect of the decrease in BC deposition since the 1980s. The future changes in BC deposition related to human activities will therefore be of critical importance for the evolution of the snow cover in the coming decades. Hence, past and future trends in snow cover and LAPs deposition cannot be investigated independently. This is crucial to assess the future regional response of mountain hydrology, water availability, and the future evolution of mountain social-ecological systems.

\section{Methods}

\section{Site description and atmospheric forcing}

\section{Study sites: French Alps and Pyrenees}

The study covers the French Alps and the Pyrenees mountain ranges. In the French Alps, most of the mountains range between 300 and $3600 \mathrm{~m}$ a.s.l. with a maximum at the Mont-Blanc with $4810 \mathrm{~m}$ a.s.l.. In this study, the Alps are split into the Northern Alps, with elevation ranging between 1500 to $3000 \mathrm{~m}$ a.s.l. and the Southern Alps with elevation ranging between 1800 to $3000 \mathrm{~m}$ a.s.l.. These elevation ranges are selected as the ones fulfilling the condition of a mean simulated snow depth $>30 \mathrm{~cm}$ over the winter period (i.e., 1st of December to 30 of April), and considering all the winters over the 1979-2018 period. Elevation above $3000 \mathrm{~m}$ a.s.l. were excluded because the meteorological forcing and the snow model Crocus were not thoroughly evaluated int this context (see details below).

The Pyrenees mountain range covers distinct mountains located in France, Spain, and Andorra, and most of them range between 300 and 3000 m a.s.l. with a maximum of 3404 m.a.s.l at the Aneto Peak (Spain). In this study, the Pyrenees are divided between the Northern and the Southern Pyrenees. The elevations selected, fulfilling the snow depth condition (i.e., an average larger than $30 \mathrm{~cm}$ for the winter period) are from 1800 to $3000 \mathrm{~m}$ a.s.l for the Northern Pyrenees and from 2100 to $3000 \mathrm{~m}$ a.s.l. for the Southern Pyrenees. 


\section{S2M meteorological reanalysis}

The S2M atmospheric reanalysis is built from the SAFRAN (Système d'Analyse Fournissant des Renseignements Atmosphériques à la Neige) meteorological analysis system (27). SAFRAN data are based on atmospheric vertical profiles simulated by an atmospheric model (ERA-40 reanalysis until 2001 and ARPEGE numerical weather prediction model after 2002). These guesses are then corrected by optimal interpolation with mainly observed surface meteorological data from various networks (automatic or manual observations). SAFRAN do not assimilate any observation above $3000 \mathrm{~m}$ a.s.1..

SAFRAN outputs include hourly meteorological variables: $2 \mathrm{~m}$ air temperature and relative humidity, precipitation amounts and phases, incoming direct and diffuse shortwave radiation, incoming longwave radiation, wind speed, cloudiness. These data are assumed to be homogeneous within a given massif. In SAFRAN geometry, the Alps and the Pyrenees are both divided into 23 massifs defined for their climatological homogeneity (51). For each massif, meteorological data depends only on elevation (one data point every $300 \mathrm{~m}$ ) and and are considered for flat surfaces.

\section{BC and dust deposition from CNRM-ALADIN63}

BC and dust deposition fluxes are obtained from the regional climate model CNRM-ALADIN63 (28). This model includes an interactive tropospheric aerosol scheme able to represent the main aerosol species such as $\mathrm{BC}$ and dust in the troposphere. These aerosols are prognostic variables, subject to transport, dry deposition and in-cloud and below-cloud scavenging. In this study, hourly output of dry and wet BC and dust deposition fluxes were used, coming from a simulation over the 1979-2018 period driven by the ERA-Interim reanalysis in order to ensure a realistic timeline of the evolution of aerosol deposition. This simulations was carried out on a regional domain covering Europe, the Mediterranean Sea and Northern Africa, at a $12 \mathrm{~km}$ horizontal resolution with 91 vertical levels. Data from this simulation have been chosen as the study performed by (32) indicated a good agreement with the observations at the Col du Lautaret (Alps, France).

Points covering the Alps and Pyrenees are extracted from this simulation, for the period 1979-2018, and downscaled to obtain BC and dust forcing in SAFRAN geometry. For that purpose, for a given massif, points located within the massif boundaries were selected. Between 5 to 10 points were selected, 
depending on the massif area. From these selected points, the hourly mean and the hourly altitudinal gradient of each variable: dry and wet BC and dust deposition is computed. The hourly gradient is then applied to the hourly mean to redistribute the data for each $300 \mathrm{~m}$ steps in agreement with SAFRAN geometry. Due to differences in precipitation timing between SAFRAN and CNRM-ALADIN63, and to agree with SAFRAN atmospheric forcing data, hourly dry and wet deposition fluxes are added and redistributed according to SAFRAN precipitation. Uncertainties of such approach are evaluated (see Method limitations).

\section{Snow cover simulations and evaluation}

\section{Simulations description}

Simulations are performed with the detailed multilayer snowpack model SURFEX/ISBA-Crocus (52). Crocus is a detailed snowpack model that includes, among others, dynamical layering, full description of the surface energy balance, specific surface area, liquid water content as prognostic variable, snow types, dry and wet snow metamorphism, and an explicit representation of LAPs (the number and types are users defined) with a fully coupled spectral radiative scheme for solar radiation absorption inside the snowpack at $20 \mathrm{~nm}$ spectral resolution (26). The radiative properties of dust and BC can be user-defined either based on LAP refractive index or on LAP mass absorption efficiency $(26,32)$. In the present study, dust is defined by the mass absorption efficiency from Caponi et al. (49) corresponding to dust PM2.5 from Libya in agreement with the study performed by Tuzet et al. (32). BC is defined from the constant refractive index advised by Bond et al. (50) (i.e. $\mathrm{m}=1.910 .79 \mathrm{i}$ ). The MAE is then scaled to obtain an MAE value at $550 \mathrm{~nm}$ of $11.25 \mathrm{~m}^{2} \mathrm{~g}^{-1}(53)$. The scaling makes it possible to implicitly account for the potential absorption enhancement due to internal particle mixing or particle coating.

The model ran over the period 1979-2018, in a semi-distributed geometry (i.e., per 300m elevation bands, for each massif, following the SAFRAN geometry). Contrary to some other applications of the SAFRAN-Crocus system, we did not extend the simulations to different aspects and slopes. To investigate the explicit effect of $\mathrm{BC}$ and dust on snow cover evolution, four configurations are set up: (i) pure simulation with no LAP $\left(\mathrm{S}_{\text {pure }}\right)$, (ii) simulation considering BC and the dust deposition fluxes $\left(\mathrm{S}_{B C+D u s t}\right)$, (iii) simulation considering $\mathrm{BC}$ deposition only $\left(\mathrm{S}_{B C}\right)$ and (iv) a simulation considering dust deposition only $\left(\mathrm{S}_{\text {Dust }}\right)$. Furthermore, the original version of Crocus model (52) considers an implicit representation 
of LAPs. Indeed, the snow albedo decreases based on the snow age and therefore implicitly considers a darkening of the snow surface. However this representation is not able to consider temporal variability of the deposition. For model evaluation, simulations $\left(\mathrm{S}_{\text {baseline }}\right)$ performed with this version are compared to the one allowing an explicit representation of BC and dust (i.e., $\mathrm{S}_{B C+D u s t}$ ).

\section{Evaluation}

1. Using satellite images

For each massif, the simulated snow cover area (SCA) and the snow cover duration (SCD) are compared to the MODIS snow product. MOD10A1 (Terra) and MYD10A1 (Aqua) snow products are downloaded from the National Snow and Ice Data Center $(54,55)$ for the period 2000-2016. The binary snow products are projected on a $500 \mathrm{~m}$ resolution grid in the same coordinate system as the DEM. Missing values, mainly due to cloud obstruction, are interpolated using a stepwise gapfilling algorithm that was evaluated in the Pyrenees (56). The simulated snow depth is projected on the same $500 \mathrm{~m}$ DEM resolution. Then, a threshold of $0.03 \mathrm{~m}$ is used to convert the simulated snow depth into snow presence or absence for each grid cell (56)). By comparing the simulated and the observed SCA, results indicate high correlations $\left(\mathrm{R}^{2}>0.75\right)$ and low RMSE (i.e., $\left.<25 \%\right)$ for all the simulations. Considering the explicit representation of $\mathrm{BC}$ and dust generally leads to a lower RMSE and a lower bias compared to the other simulations (Supplementary text, Supplementary Fig. S7).

2. Comparison with snow depth measurements

In order to strengthen the evaluation, simulations are performed at 495 weather station locations over the French Alps and Pyrenees, covering elevation ranges from 1200 to 2700, over the period 1983-2018. The evaluation is done by comparing the simulated and measured daily snow depth variations corresponding to melt (57) (Supplementary text). Considering the explicit representation of $\mathrm{BC}$ and dust generally leads to a lower bias compared to the other simulations (Supplementary Fig. S8). 


\section{Strategy of BC and dust contribution quantification}

\section{On the snow cover duration}

First, the snow melt-out date (SMOD), defined as the last date of the longest period with at least $30 \mathrm{~cm}$ of snow is computed for each simulation. Then, to quantify the impact of BC and dust on the shortening of the season, the SMOD differences between $\mathrm{S}_{\text {pure }}$ and $\mathrm{S}_{B C+\text { Dust }}$ are computed for each massif, elevations, and years. The differences (i.e., $\Delta_{S M O D}$ ) are given by elevation and locations (Fig. 1), and the spread corresponds to the annual variability. The differences are also quantified for the simulation between $S_{\text {pure }}$ and $S_{B C}$ and $S_{D u s t}$ to evaluate the influence of BC and dust deposition on the snow cover duration separately (Fig. 1) Finally, differences between $S_{\text {pure }}$ and $\mathrm{S}_{\text {baseline }}$ are also shown.

2. On the annual variability of the snow cover

A statistical approached based on the variance analysis (ANOVA) is used to evaluate the contribution of the BC and dust on the SMOD annual variability. The detailed method is described in Geoffroy et al. (31) (following the Eq. reported in the Supplementary text). Here, the contribution of the two parameters "meteorological forcing" and "BC+Dust" to the SMOD variance is computed (Fig. 2).

3. On the trend in snow cover

The trends in meteorological forcing (temperature and solid precipitation), BC and dust, are computed over the 1979-2018 period, and a Student test (t-test with a 0.05 confidence interval) is applied to evaluate the significance. The trends in simulated snow cover (SMOD) and CMD of $\mathrm{S}_{\text {pure }}$ and $\mathrm{S}_{B C+D u s t}$ are quantified following the same method (Fig. 3). Then, for each year, the SMOD differences between $S_{\text {pure }}$ and $S_{B C+D u s t}$ (and also $S_{B C}$ and $S_{D u s t}$ separately) is computed, in order to obtain a dataset (39 years) from these differences. The trend of this dataset is then computed and its significance is evaluated following the t-test with a 0.05 confidence interval. This method allows to evaluate the significance of the impact of the BC and dust on the trend. 


\section{Hydrological impacts}

To evaluate the impact of $\mathrm{BC}$ and dust on the hydrology, the center of mass date (CMD) of the runoff from snowmelt is computed for each simulation. The CMD is defined as the date for which $50 \%$ of the total annual runoff from snowmelt is reached (34). The simulated runoff from snowmelt by Crocus is projected on a $500 \mathrm{~m}$ DEM for the Alps and the Pyrenees. The Northern and Southern Alps and the Pyrenees are considered as four distinct catchments and the total runoff is computed for each catchment for the 39 years. The mean with the standard deviation (indicating to the temporal variability) is computed for each catchment considering pure simulations and simulations accounting for $\mathrm{BC}$ and dust, to evaluate the impact of the BC and dust on the runoff amount and timing (Fig. 4). Then, the impact of BC and dust on the annual variability of the CMD is evaluated following the same method as for the snow cover described above (Supplementary Fig. S4). The same method as for the snow cover is also applied to evaluate the impact of the $\mathrm{BC}$ and dust on the CMD trends (Fig. 3).

\section{Method limitations}

\section{Forcing uncertainties}

1. Trends

As atmospheric and snow cover trends studied here, originate from only one surface model forced with only one meteorological reanalysis $(\mathrm{S} 2 \mathrm{M})$, comparisons to other models and observations are required to reinforce our conclusions. All climatological reconstructions are affected by irreducible uncertainties in the obtained trends due to the temporal heterogeneities of the number and quality of the data upon which they rely. In particular, Vidal et al. (58) demonstrate that the heterogeneities of available temperature measurements can significantly affect local temperature trends in S2M. This limitation is expected to be less important when considering large scale signals as in this paper. However, Beaumet et al. (59) and Ménégoz et al. (60) revealed some large scale differences in temperature and precipitation trends between S2M analyses and the Regional Climate Model, MAR, forced by ERA20C reanalysis at the boundaries but not assimilating any observation inside the simulation domain. Similar discrepancies were obtained in Switzerland by Scherrer and Kotlarski (61) comparing similar products between S2M and another atmospheric model. However, 
the snow cover trend from our simulations accounting for BC and dust is in line with the observed trends. In our simulations, the SMOD trend in the Northern Alps at around $1500 \mathrm{~m}$ a.s.l is $-4.0 \pm 0.6$ days per decade, comparable to the trend observed at Col de Porte (-4.1 days per decade, $1325 \mathrm{~m}$ a.s.1., 1960-2018) (40). In addition, the averaged trend of $-5.3 \pm 0.6$ days per decade (3.0\%) simulated for the Northern Alps considering elevation ranging between 1500 and $2400 \mathrm{~m}$ a.s.l. is in good agreement with an averaged earlier snowmelt of 5.7 days per decade observed at 11 stations (covering elevations from 1139 to 2540 m a.s.1) in the Swiss Alps over the 1970-2015 period (41). In a study based on 202 to 688 stations in the European Alps over the 1971-2019 period, the SCD computed over the March-May season decreases by -7.8 to $-0.7 \%$ depending on elevation (1000 to $3000 \mathrm{~m}$ a.s.1.) and orientation (North or South) (7). The mean relative change of $3.0 \%$ from our simulations is within the range of this study. In the Pyrenees, the absence of significant trend of the SMOD at $2100 \mathrm{~m}$ a.s.l. since 1980 is in agreement with the work of Lopez-Moreno et al. (42). Besides, the results of our study are mostly based on relative differences between simulations and not on absolute value, therefore mitigating the impact of uncertainties in the meteorological variables and in the surface model.

\section{SAFRAN reanalysis}

In snow modeling, significant uncertainties are bought by the meteorological forcing (62). Uncertainties in the SAFRAN meteorological reanalysis has been estimated by previous studies $(63,64)$ and are highly variable in space. While air temperature biases have not been reported compared to observations at different locations, radiatif and precipitation biases have been observed. For instance, Queno et al. (57) reported a bias of the shortwave radiation reaching $25 \%$ in the Pyrenees. Vionnet et al. (65) showed and under-estimation of precipitation amount in the Alps at high elevation. To consider these uncertainties, ensemble methods on the meteorological forcing are increasingly used. By applying this method, the simulated SMOD uncertainty can reach one month (66). However, in our study, this impact of this uncertainty is minimized as our conclusions are bases on relative differences between simulations.

3. BC and dust

$\mathrm{BC}$ and dust deposition used to force the snowpack model is from only one atmospheric model and 
could be taken with caution. Still, BC and dust deposition from CNRM-ALADIN63 have been evaluated by Tuzet et al., (32) at the Col du Lautaret (French Alps) over two snow season. They showed that compared to the radiative forcing and BC and dust content at the snow surface, simulated deposition from CNRM-ALADIN63 performs really well $\left(\mathrm{R}^{2}=0.78\right.$ between the simulated and measured absorption and no significant bias are observed between the modeled specific surface area and the measurements). In addition, annual BC deposition and trend from CNRM-ALADIN63 is in total agreement with BC deposition modeled by GFDL-AM4 $(45,67)$ (Supplementary Fig. S2). While dust load from CNRM-ALADIN63 are higher than the one from GFDL-AM4, both model indicate no significant trend in dust deposition over the period 1980-2014.

The $\mathrm{BC}$ and dust downscaling method is also prone to uncertainties. Different approaches are therefore been tested. Firstly, we tested the impact of the number of points selected in each massif with and without considering a weight depending on the point location using the downscaling methodology. Results do not lead to significant differences in total BC and dust deposition (differences lower than 5\% ) when computing this deposition with a different number of points selected for a given massif. Second, another method to compute the altitudinal gradient, used to redistribute the $\mathrm{BC}$ and dust deposition, is tested. This gradient is computed using the concentration profiles of the $\mathrm{BC}$ and dust in the atmosphere instead of the $\mathrm{BC}$ and dust deposition. With the hypothesis that the atmospheric profile is conserved for the altitudinal variation of the deposition, the monthly gradient is computed from the monthly data of the $\mathrm{BC}$ and dust concentration profile available. In this case, dry and wet deposition cannot be separated and the gradient is relatively homogeneous for all the locations. The maximum difference in BC and dust deposition between the two methods is $30 \%$ for the BC and $45 \%$ for the dust deposition. This method hasn't been chosen due to the unrealistic homogeneous gradient obtained. Finally, the dry and wet distribution method following the SAFRAN precipitation events can be questionable. A sensitivity test by performing a simulation considering all the fluxes as dry deposition indicated a mean difference lower than one day (with a maximum of 4 days observed at highest elevations) compared to the simulation performed with the method described in this study. Larger differences are observed when considering all the fluxes as wet deposition where a maximum of -15 days is observed at the highest elevation with a 
mean of 4 days. Yet, this uncertainty is lower than the SMOD differences calculated related to the effect of BC and dust on the snow cover duration.

\section{Model uncertainties}

\section{Optical properties of $\mathrm{BC}$ and dust}

The choice of dust refractive index and mass absorption coefficients also implies some uncertainties. In this study, value for Saharan Libya PM2-5 (49) are chosen: a mass absorption efficiency at $400 \mathrm{~nm}$ of $11010^{-3} \mathrm{~m}^{2} \mathrm{~g}^{-1}$ and a dust Angstorm exponent equal to 4.1. This choice was made as Saharan dust is the primary source of dust deposition in European mountainous areas and as Tuzet et al. (32) demonstrated based on spectral reflectance measurements that this spectral signature agrees well with the measured spectrum for two winter seasons. However, this spectral signature is expected to vary significantly with the source location which varies over time. Simulations performed by changing this spectral signature, with a mass absorption efficiency at 400nm ranging between $2710^{-3} \mathrm{~m}^{2} \mathrm{~g}^{-1}$ (corresponding to the source Sahel - Bodélé PM10) and $63010^{-3} \mathrm{~m}^{2}$ $\mathrm{g}^{-1}$ (for dust PM2-5 from Sahel - Mali). The Angstorm exponent is equal to 3.3 (Bodélé) and 3.4 (Mali). This sensitivity study allows quantifying the uncertainty related to the spectral signature chosen (Supplementary Fig. S5). Depending on this calibration, the median of the $\Delta$ SMOD at 2100 m a.s.l. vary between 15 to 25 and 12 to 23 for the North and South Alps respectively, and between 11 to 20 and 10 to 21 for the North and South Pyrenees respectively. The median of the $\triangle \mathrm{SMOD}$ with the spectral signature chosen in this study is closer to the lower median (i.e. 19 (15) for the North (South) Alps and 13 for both the North and South Pyrenees), suggesting that the effect of dust reported in this study might be under-estimated, especially for Saharan event from location close to Mali. Finally, additional uncertainties are also associated with the modelling of BC absorption efficiency in snow. Indeed, the evolution of this parameter are still poorly understood with variations of at least a factor 2 reported in the literature (e.g. Tuzet et al. (48) and references therein).

\section{Scavenging of $B C$ and dust}

In this study the scavenging of impurities in the snowpack was not considered (32). Indeed, the lack 
of quantitative observations of LAPs percolation at the snow surface in presence of melt water does not allow a proper evaluation of this effect. Moreover, Crocus percolation schemes are quite simple and are expected to be entached with many uncertainties. A sensitivity test has nevertheless been performed, allowing $20 \%$ of the $\mathrm{BC}$ (5\% of the dust) to scavenged with the water percolation (26). This leads to a negligible effect (i.e. a median of the $\Delta$ SMOD variation at $2100 \mathrm{~m}$ a.s.l. of 2 days for the North Alps and 1 day for the South Alps).

\section{Representation in snow physics}

Large uncertainties remain also in the representation of the snow physics, and Skiles and Painter (68) quantified a SMOD difference around 30 days depending on the complexity of the snow model chosen (degree-day snow model vs detailed snow model). Using an ensemble approach considering 35 different state-of-the art parameterisations in Crocus, Dumont et al. (29) indicates a SMOD variation around 5 days, highlighting the uncertainty related to the selected snow physic in the model. In this study, we quantified the model uncertainty using and ensemble approach considering 35 different state-of-the art parameterisations in Crocus (69) to simulate the delta SMOD at 2100 m a.s.l. (Supplementary Fig. S6). Uncertainties related to model physic choice and location (i.e. box plot size of the ensemble simulations) is within the same range than the location uncertainty (i.e. the box plot size of the deterministic simulation in Supplementary Fig. S6).

\section{Geometry of the simulations}

Simulations are performed in a semi-distributed geometry only considering a flat aspect. This is because the slope and aspect represent a huge amount of additional data, complex to be considered in the simulations. Still, with a simulation considering the slope and aspect, we expect a higher impact of the $\mathrm{BC}$ and dust deposition on the snowpack evolution for southern slopes compared to flat areas (and the opposite for the Northern slopes). Southern slopes are indeed exposed to considerably higher solar radiation. 


\section{References}

1. Barnett, T. P., Adam, J. C. \& Lettenmaier, D. P. Potential impacts of a warming climate on water availability in snow-dominated regions. Nature 438, 303-309 (2005).

2. Mankin, J. S. \& Diffenbaugh, N. S. Influence of temperature and precipitation variability on near-term snow trends. Climate Dynamics 45, 1099-1116 (2015).

3. Ernakovich, J. G. et al. Predicted responses of arctic and alpine ecosystems to altered seasonality under climate change. Global Change Biology 20, 3256-3269 (2014).

4. Hoegh-Guldberg, O. et al. Impacts of $1.5 \mathrm{c}$ global warming on natural and human systems. Global warming of 1.5 C. An IPCC Special Report (2018).

5. Flanner, M. G., Shell, K. M., Barlage, M., Perovich, D. K. \& Tschudi, M. Radiative forcing and albedo feedback from the northern hemisphere cryosphere between 1979 and 2008. Nature Geoscience 4, $151-155(2011)$.

6. Hock, R. et al. High mountain areas: Ipcc special report on the ocean and cryosphere in a changing climate (2019).

7. Matiu, M. et al. Observed snow depth trends in the european alps: 1971 to 2019. The Cryosphere 15, 1343-1382 (2021).

8. Hartmann, D. et al. Observations: Atmosphere and Surface, book section 2, 159-254 (Cambridge University Press, Cambridge, United Kingdom and New York, NY, USA, 2013). URL wWw.climatechange2013.org.

9. Wiscombe, W. J. \& Warren, S. G. A model for the spectral albedo of snow. i: Pure snow. Journal of Atmospheric Sciences 37, 2712-2733 (1980).

10. Painter, T. H., Skiles, S. M., Deems, J. S., Brandt, W. T. \& Dozier, J. Variation in rising limb of colorado river snowmelt runoff hydrograph controlled by dust radiative forcing in snow. Geophysical Research Letters 45, 797-808 (2018). 
11. Warren, S. G. Light-absorbing impurities in snow: a personal and historical account. Frontiers in Earth Science 6, 250 (2019).

12. Skiles, S. M., Flanner, M., Cook, J. M., Dumont, M. \& Painter, T. H. Radiative forcing by lightabsorbing particles in snow. Nature Climate Change 8, 964-971 (2018).

13. Dumont, M. et al. Contribution of light-absorbing impurities in snow to greenland's darkening since 2009. Nature Geoscience 7, 509-512 (2014).

14. Sterle, K. M., McConnell, J. R., Dozier, J., Edwards, R. \& Flanner, M. G. Retention and radiative forcing of black carbon in eastern sierra nevada snow. The Cryosphere 7, 365-374 (2013). URL https://tc.copernicus.org/articles/7/365/2013/.

15. Flanner, M. G., Zender, C. S., Randerson, J. T. \& Rasch, P. J. Present-day climate forcing and response from black carbon in snow. Journal of Geophysical Research: Atmospheres 112 (2007).

16. Painter, T. H. et al. End of the little ice age in the alps forced by industrial black carbon. Proceedings of the national academy of sciences 110, 15216-15221 (2013).

17. Lim, S. et al. Black carbon variability since preindustrial times in the eastern part of europe reconstructed from mt. elbrus, caucasus, ice cores. Atmospheric Chemistry and Physics 17 (2017).

18. Kutzner, R. D. et al. Long-term monitoring of black carbon across germany. Atmospheric Environment 185, 41-52 (2018).

19. Kaspari, S., Painter, T. H., Gysel, M., Skiles, S. \& Schwikowski, M. Seasonal and elevational variations of black carbon and dust in snow and ice in the solu-khumbu, nepal and estimated radiative forcings. Atmospheric Chemistry and Physics 14, 8089-8103 (2014).

20. Di Mauro, B. et al. Mineral dust impact on snow radiative properties in the european alps combining ground, uav, and satellite observations. Journal of Geophysical Research: Atmospheres 120, 6080_ $6097(2015)$

21. Réveillet, M. et al. Dépôts massifs de poussières sahariennes sur le manteau neigeux dans les Alpes et les Pyrénées du 5 au 7 février 2021 : Contexte, enjeux et résultats préliminaires Version du 3 
mai 2021. Technical Report, CNRM, Université de Toulouse, Météo-France, CNRS (2021). URL https://hal.archives-ouvertes.fr/hal-03216273.

22. Sarangi, C. et al. Dust dominates high-altitude snow darkening and melt over high-mountain asia. Nature Climate Change 10, 1045-1051.

23. Ginoux, P. et al. Sources and distributions of dust aerosols simulated with the gocart model. Journal of Geophysical Research: Atmospheres 106, 20255-20273 (2001).

24. Chedin, A., Capelle, V. \& Scott, N. Detection of iasi dust aod trends over sahara: How many years of data required? Atmospheric Research 212, 120-129 (2018).

25. Di Mauro, B., Garzonio, R. \& Baccolo, G. e. a. Glacier algae foster ice-albedo feedback in the european alps. Scientific Reports 10 (2020).

26. Tuzet, F. et al. A multilayer physically based snowpack model simulating direct and indirect radiative impacts of light-absorbing impurities in snow. The Cryosphere 11 (2017).

27. Vernay, M. et al. The S2M meteorological and snow cover reanalysis in the French mountainous areas (1958-present), Data set, AERIS (2019).

28. Nabat, P. et al. Modulation of radiative aerosols effects by atmospheric circulation over the euro-mediterranean region. Atmospheric Chemistry and Physics 20, 8315-8349 (2020). URL https://acp.copernicus.org/articles/20/8315/2020/.

29. Dumont, M. et al. Accelerated snow melt in the Russian Caucasus mountains after the Saharan dust outbreak in March 2018. Journal of Geophysical Research: Earth Surface 125 (2020).

30. Essery, R., Morin, S., Lejeune, Y. \& Ménard, C. B. A comparison of 1701 snow models using observations from an alpine site. Advances in Water Resources 55, 131-148 (2013).

31. Geoffroy, O., Saint-Martin, D. \& Ribes, A. Quantifying the sources of spread in climate change experiments. Geophysical Research Letters 39 (2012). 
32. Tuzet, F. et al. Quantification of the radiative impact of light-absorbing particles during two contrasted snow seasons at col du lautaret (2058 m asl, french alps). The Cryosphere Discussions 1-38 (2020).

33. Vincent, J. et al. Variability of mineral dust deposition in the western mediterranean basin and south-east of france (2016).

34. McCabe, G. J. \& Clark, M. P. Trends and variability in snowmelt runoff in the western united states. Journal of Hydrometeorology 6, 476-482 (2005).

35. Bard, A. et al. Trends in the hydrologic regime of alpine rivers. Journal of Hydrology 529, 18231837 (2015).

36. Pey, J. et al. Snow impurities in the central pyrenees: From their geochemical and mineralogical composition towards their impacts on snow albedo. Atmosphere 11, 937 (2020).

37. Ningombam, S. S. et al. Long-term (1995-2018) aerosol optical depth derived using ground based aeronet and skynet measurements from aerosol aged-background sites. Atmospheric Pollution Research 10, 608-620 (2019).

38. Sharma, S. et al. Widespread loss of lake ice around the northern hemisphere in a warming world. Nature Climate Change 9, 227-231 (2019).

39. Kutuzov, S. et al. The elbrus (caucasus, russia) ice core record-part 2: history of desert dust deposition. Atmospheric Chemistry and Physics 19 (2019).

40. Lejeune, Y. et al. 57 years (1960-2017) of snow and meteorological observations from a mid-altitude mountain site (col de porte, france, 1325 m of altitude). Earth System Science Data 11, 71-88 (2019). URL https://essd.copernicus.org/articles/11/71/2019/.

41. Klein, G., Vitasse, Y., Rixen, C., Marty, C. \& Rebetez, M. Shorter snow cover duration since 1970 in the swiss alps due to earlier snowmelt more than to later snow onset. Climatic Change 139, 637-649 (2016). 
42. López-Moreno, J. et al. Long-term trends (1958-2017) in snow cover duration and depth in the pyrenees. International Journal of Climatology (2020).

43. Sun, J. et al. Decreasing trends of particle number and black carbon mass concentrations at 16 observational sites in germany from 2009 to 2018. Atmospheric Chemistry and Physics 20, 7049$7068(2020)$.

44. Grange, S. K., Lötscher, H., Fischer, A., Emmenegger, L. \& Hueglin, C. Evaluation of equivalent black carbon source apportionment using observations from switzerland between 2008 and 2018 . Atmospheric Measurement Techniques 13 (2020).

45. Zhao, M. et al. The gfdl global atmosphere and land model am4. 0/1m4. 0: 1. simulation characteristics with prescribed ssts. Journal of Advances in Modeling Earth Systems 10, 691-734 (2018).

46. Hoham, R. W. \& Remias, D. Snow and glacial algae: A review1. Journal of phycology 56, 264-282 (2020).

47. Stewart, A. et al. Altitudinal zonation of green algae biodiversity in the french alps. Frontiers in Plant Science 12, 1066 (2021).

48. Tuzet, F. et al. Influence of light-absorbing particles on snow spectral irradiance profiles. The Cryosphere 13, 2169-2187 (2019).

49. Caponi, L. et al. Spectral-and size-resolved mass absorption efficiency of mineral dust aerosols in the shortwave spectrum: a simulation chamber study. Atmospheric Chemistry and Physics 17, 7175-7191 (2017).

50. Bond, T. C. \& Bergstrom, R. W. Light absorption by carbonaceous particles: An investigative review. Aerosol science and technology 40, 27-67 (2006).

51. Durand, Y. et al. Reanalysis of $44 \mathrm{yr}$ of climate in the french alps (1958-2002): methodology, model validation, climatology, and trends for air temperature and precipitation. Journal of Applied Meteorology and Climatology 48, 429-449 (2009). 
52. Vionnet, V. et al. The detailed snowpack scheme crocus and its implementation in surfex v7. 2 (2012).

53. Hadley, O. L. \& Kirchstetter, T. W. Black-carbon reduction of snow albedo. Nature Climate Change 2, 437-440 (2012).

54. Hall, D. K., Riggs, G. A. \& Salomonson, V. V. Modis snow and sea ice products. Earth science satellite remote sensing 154-181 (2006).

55. Hall, D. K. \& Riggs, G. A. Accuracy assessment of the modis snow products. Hydrological Processes: An International Journal 21, 1534-1547 (2007).

56. Gascoin, S. et al. A snow cover climatology for the pyrenees from modis snow products (2015).

57. Quéno, L., Karbou, F., Vionnet, V. \& Dombrowski-Etchevers, I. Satellite products of incoming solar and longwave radiations used for snowpack modelling in mountainous terrain. Hydrology and Earth System Sciences Discussions 1-33 (2017).

58. Vidal, J. P., Martin, E., Franchistéguy, L., Baillon, M. \& Soubeyroux, J.-M. A 50-year highresolution atmospheric reanalysis over france with the safran system. International Journal of Climatology 30, 1627-1644 (2010).

59. Beaumet, J. et al. Twentieth century temperature and snow cover changes in the french alps using a high-resolution regional climate model and reanalyses. Regional Environmental Change (under review).

60. Ménégoz, M. et al. Contrasting seasonal changes in total and intense precipitation in the european alps from 1903 to 2010. Hydrology and Earth System Sciences Discussions 1-37 (2020).

61. Scherrer, S. C. Temperature monitoring in mountain regions using reanalyses: Lessons from the alps. Environmental Research Letters 15, 044005 (2020).

62. Raleigh, M., Lundquist, J. \& Clark, M. Exploring the impact of forcing error characteristics on physically based snow simulations within a global sensitivity analysis framework. Hydrology \& Earth System Sciences 19 (2015). 
63. Quintana-Segui, P. et al. Analysis of near-surface atmospheric variables: Validation of the safran analysis over france. Journal of applied meteorology and climatology 47, 92-107 (2008).

64. Charrois, L. et al. On the assimilation of optical reflectances and snow depth observations into a detailed snowpack model (2016).

65. Vionnet, V. et al. Sub-kilometer precipitation datasets for snowpack and glacier modeling in alpine terrain. Frontiers in Earth Science 7, 182 (2019).

66. Cluzet, B. et al. Croco_v1. 0: a particle filter to assimilate snowpack observations in a spatialised framework. Geoscientific Model Development Discussions 1-36 (2020).

67. Zhao, M. et al. The gfdl global atmosphere and land model am4. 0/lm4. 0: 2. model description, sensitivity studies, and tuning strategies. Journal of Advances in Modeling Earth Systems 10, 735-769 (2018).

68. Skiles, S. M. \& Painter, T. H. Toward understanding direct absorption and grain size feedbacks by dust radiative forcing in snow with coupled snow physical and radiative transfer modeling. Water Resources Research 55, 7362-7378 (2019). URL https://agupubs.onlinelibrary.wiley.com/doi/abs/10.1029/2018WR024573. https://agupubs.onlinelibrary.wiley.com/doi/pdf/10.1029/2018WR024573.

69. Lafaysse, M. et al. A multiphysical ensemble system of numerical snow modelling. The Cryosphere 11, 1173-1198 (2017).

Acknowledgements. The authors thank Florent Dominé and Delphine Six for helpful conversations.

Funding. CNRM/CEN and IGE are part of Labex OSUG@2020 (investissement d'avenir - ANR10 LABX56). This study was supported by the ANR program ANR-16-CE01-0006 EBONI; the INSU/LEFE project ASSURANCE, and the CNES APR grant MIOSOTIS. This research was at least partially supported by Lautaret Garden-UMS 3370 (Univ.Grenoble Alpes, CNRS, SAJF, 38000 Grenoble, France), member of AnaEE-France (ANR-11-INBS-0001AnaEE-Services, Investissements d'Avenir frame) and 
of the eLTER-Europe network (Univ. Grenoble Alpes, CNRS, LTSER Zone Atelier Alpes, 38000 Grenoble, France). As part of the project CDP TRAJECTORIES, M. M. has been funded by the French National Research Agency in the framework of the "Investissements d'avenir" programme (ANR-15-IDEX-02).

Author Contributions. M. R. led the study and performed the simulations and analysis. M.D. designed the study. M.R. and M.D. wrote the paper with contributions from all co-authors. S.G. provided the MODIS data and contributed to the analysis. F.T., M.L. and R.N. implemented the Crocus version with explicit representation of LAPs. P.N. and P.G. provided atmospheric simulations including LAPs deposition and contributed to the analysis. A.R. contributed the ANOVA and trends computations and analysis. M.M. contributed to the downscaling method for the LAPs fluxes and to the analysis.

Competing Interests. The authors declare that they have no competing interests.

Data and code availability. The dataset will be published on an open-access platform (with a DOI) after the review process. While it is not yet implemented in an official SURFEX release, the code will be downloadable from a specific tag of the git repository maintained by Centre d'Études de la Neige upon publication of the paper. The full procedure and documentation to access this git repository can be found at : https://opensource.cnrm-game-meteo.fr/projects/snowtools_git/wiki. Tartes model is available here: http://snowtartes.pythonanywhere.com/ (web application and Python module download). 


\section{Figures}

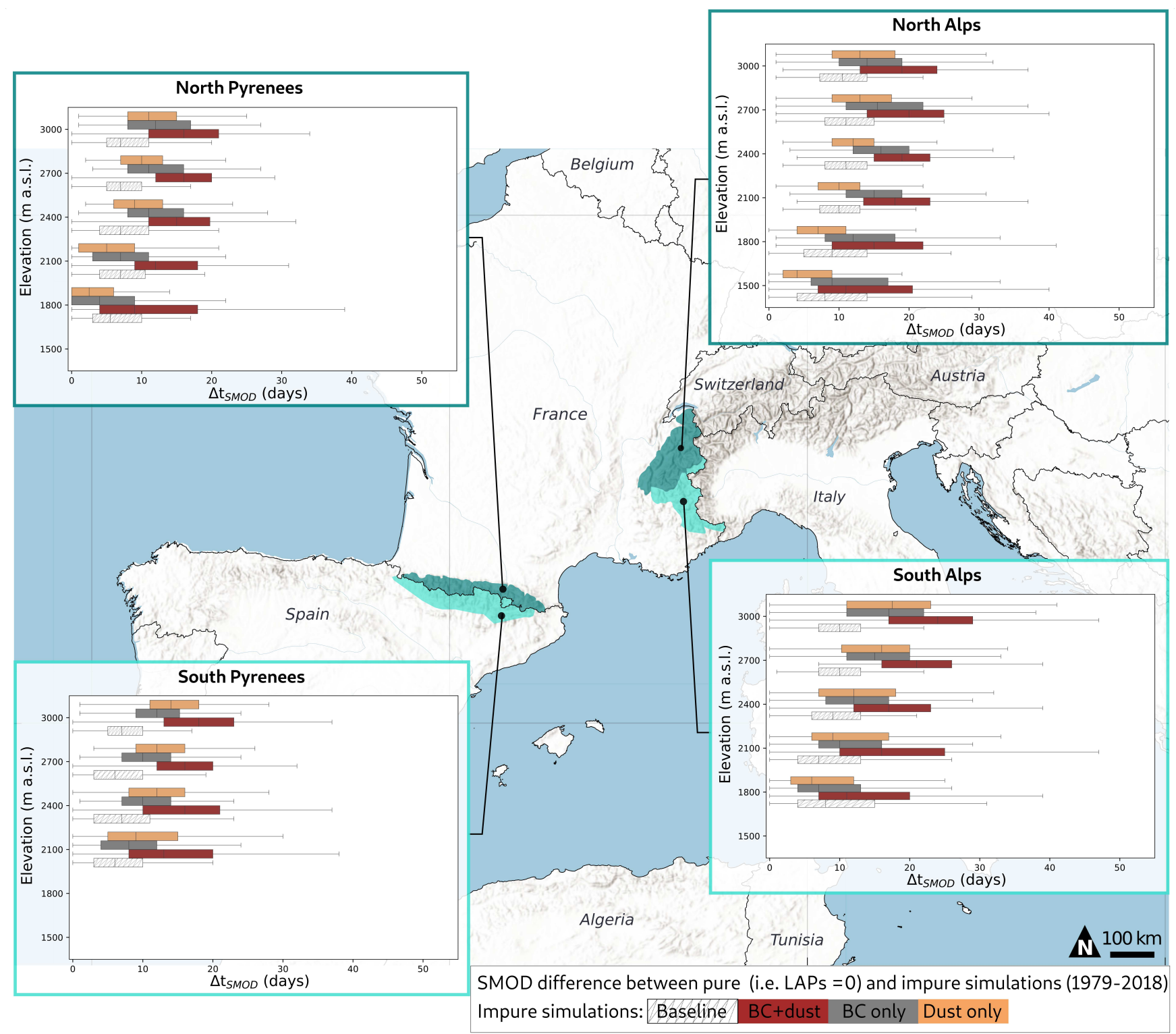

Fig. 1: Shortening of the snow season related to $\mathrm{BC}$ and dust deposition This shortening is computed as the difference in snow melt-out date (SMOD) between the pure snow simulations and all the configurations: simulations considering BC and dust (brown), only BC (grey), only dust (orange), considering implicitly the LAPs (i.e. an albedo decrease based on the snow age only, green). SMOD differences are computed as a function of the elevation, computed considering the entire study period (i.e., 1978-2018), for the North and South Pyrenees (left) and the North and South Alps (right). The boxes show the quartiles of the distribution corresponding to the inter-annual and spatial variability. Minimum/maximum ranges (excluding outliers) are indicated by the whiskers. Only elevations with a mean SD $>30 \mathrm{~cm}$ over the winter period (i.e. 1st of December to 30 of April) are represented. 


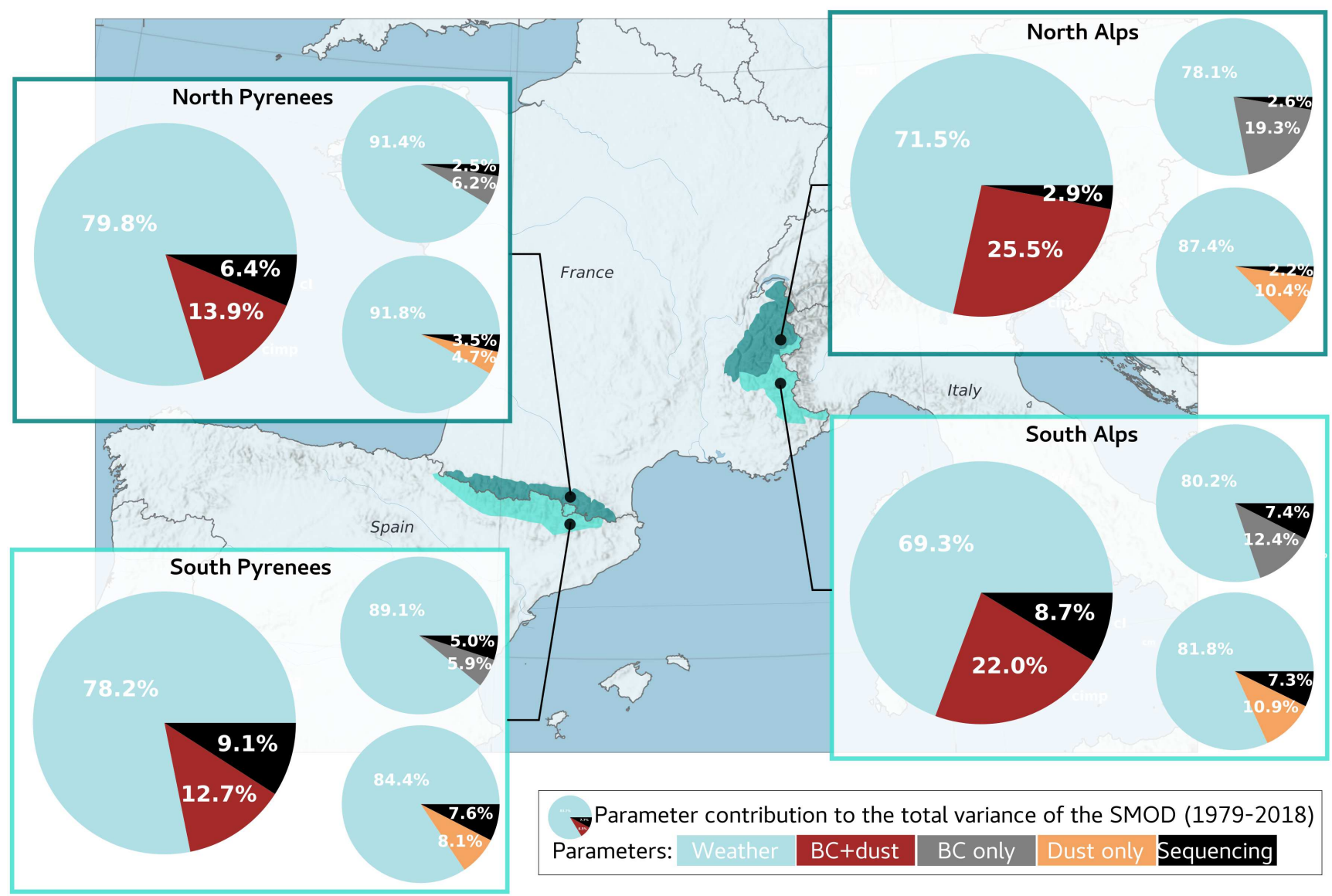

Fig. 2: Contribution of the meteorological conditions and $\mathrm{BC}$ and dust to the variance of the SMOD. Contributions computed over the 1979-2018 period at $2100 \mathrm{~m}$ a.s.l.. for the North and South Pyrenees (left), North and South Alps (right). Larger circles indicate contributions of the parameters considering the role of $\mathrm{BC}+\mathrm{Dust}$ (brown) and smaller circles represent the contribution of BC (grey) and dust (orange) separately. The sequencing term (black) indicates the contribution of $\mathrm{BC}$ and dust and meteorological forcing, and is due to the dependence of the $\mathrm{BC}$ and dust contribution to the meteorological conditions. 


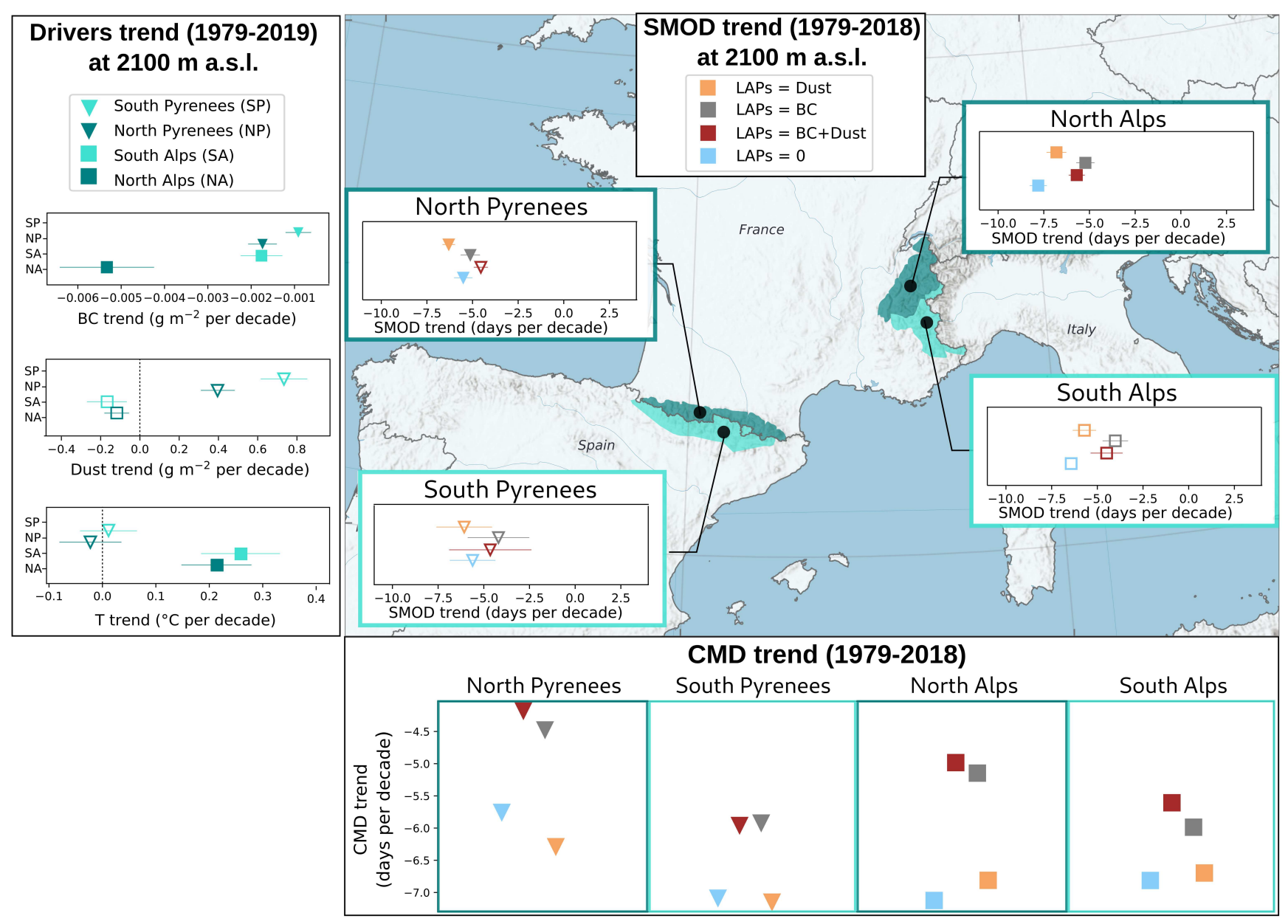

Fig. 3: Trends in air temperature (at $2 \mathrm{~m}$ above the surface), BC and dust deposition, SMOD and center of mass date (CMD) over 1979-2018. Trends are from temporal series computed from annual values at $2100 \mathrm{~m}$ a.s.1.. Trends are represented as the the best estimate and $90 \%$ confidence range, per area (North Alps, South Alps, North Pyrenees and South Pyrenees). Only markers of significant trends (t-test 0.05) are filled in. Error bars represent the spatial variability. Only elevations with a mean SD $>30$ $\mathrm{cm}$ over the winter period (i.e. 1st of December to 30 of April) are represented. 

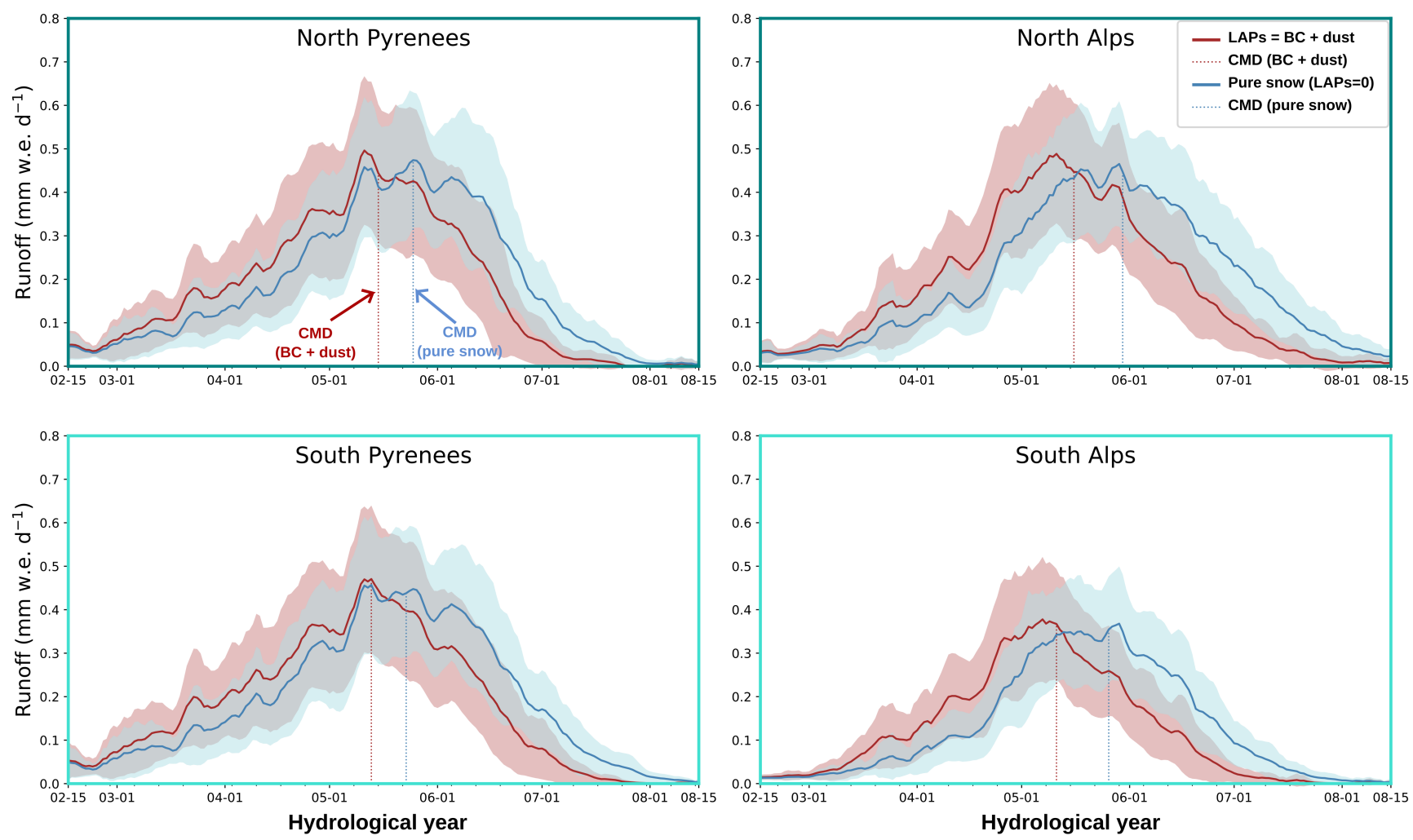

Fig. 4: Runoff from snowmelt averaged over the period 1979-2018 (solid line) with the standard deviation (shaded areas) representing the annual variability. Pure simulations are represented in blue and simulations considering the effect of $\mathrm{BC}$ and dust are in red. The center of mass date of each simulation, defined as the date for which half of the total annual runoff from snowmelt is reached, are indicated by the dashed lines. 


\section{Supplementary Files}

This is a list of supplementary files associated with this preprint. Click to download.

- ReveilletetalNCommSuppMat.pdf 